\title{
14. Technological Progress in Developing Renewable Energies
}

\author{
Kejun Jiang
}

\section{Recent developments in renewable energy in China}

\section{General picture}

China is now a leading player in renewable energy development. Annual capacity increases for renewable energy in China account for one-third of the global total. Industry growth has been especially strong since 2011, with annual growth in wind energy of 22 per cent and 110 per cent for solar energy. Since 2015, China has been the world's largest consumer of modern renewable energy. Figure 14.1 illustrates the growth in installed capacity of renewable energy in hydropower, wind power, solar photovoltaic (PV) and biomass in China for the 15 years after 2000.

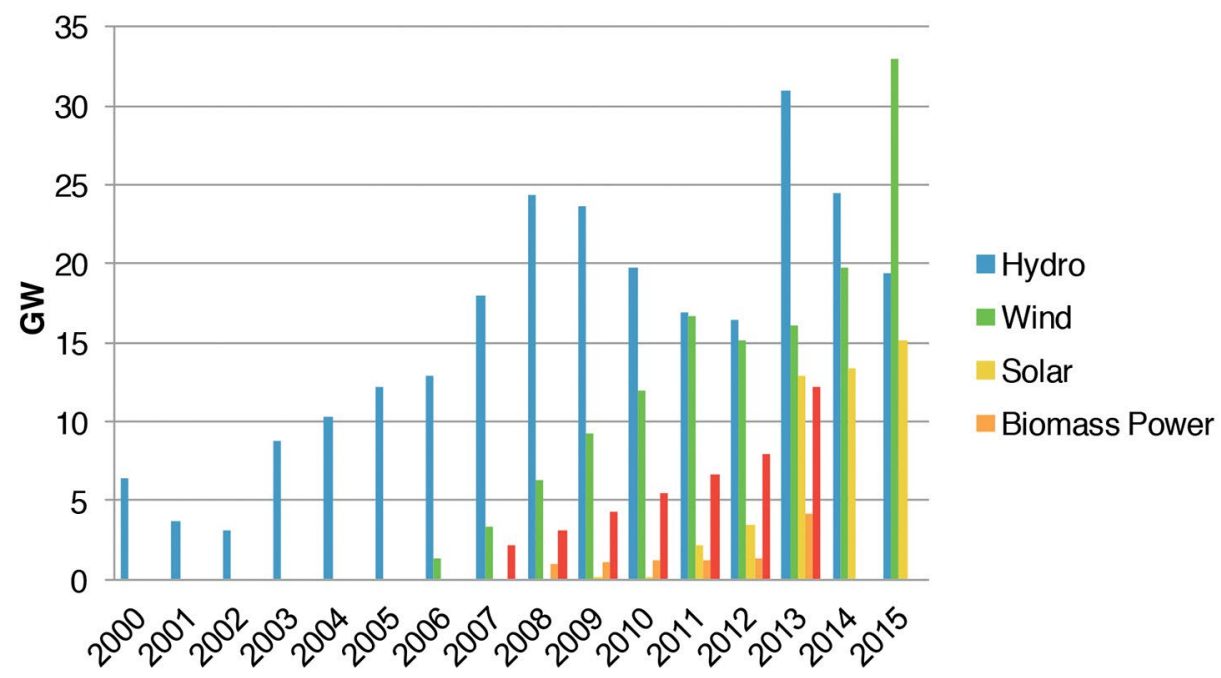

Figure 14.1 Newly installed capacity for selected renewable energy generation in China (gigawatts (GW))

Source: CEC (2017). 
Figure 14.1 also draws attention to the importance of policy in promoting the development of renewables in China. After feed-in tariffs (FITs) were announced, wind power and solar power started to expand by largely increasing their annual newly installed capacity.

As an important player in the renewable energy market, China is the leading country, followed by United States, Brazil, Germany and Canada. China has more than one-quarter of the world's total installed renewable power capacity, of some 500 gigawatts $(\mathrm{GW})$. More than half of this, about $296 \mathrm{GW}$, is hydropower. In terms of non-hydro capacity, the countries with the greatest installed capacity are China, the United States and Germany, followed by Japan, India, Italy and Spain (Figures 14.2 and 14.3).

Global new investment in renewable power and fuels increased to US\$285.9 billion in 2015 (not including large hydropower projects that exceed 50 megawatts $(\mathrm{MW})$ ), which is 5 per cent higher than in 2014 and exceeds the previous record of US\$278.5 billion, set in 2011 (Ren21 2016).

Of the total of US\$285.9 billion, China's share of investment was US\$102.9 billion-up 17 per cent year-on-year and accounting for 36 per cent of the global total. Most of China's renewables investment was in asset financing, with US\$5.5 billion invested in small-scale projects. Wind power led investments in utility-scale projects, of US $\$ 47.6$ billion, while US $\$ 44.3$ billion was put into solar power. Offshore wind energy had a breakthrough year in China, with nine projects financed with an around US\$5.6 billion. The country also put large investment in large hydropower; $16 \mathrm{GW}$ of new projects started construction during the year, a large portion of which was large hydro.

Overall, this was equivalent to more than one-third of global renewable energy installations in 2015, and generated 3.5 million jobs. In addition, employment in large-scale hydropower in China supported around 440,000 direct jobs, most of which were in construction. 
Renewable Power Capacities, in World, EU-28, BRICS and Top Seven Countries, End-2015
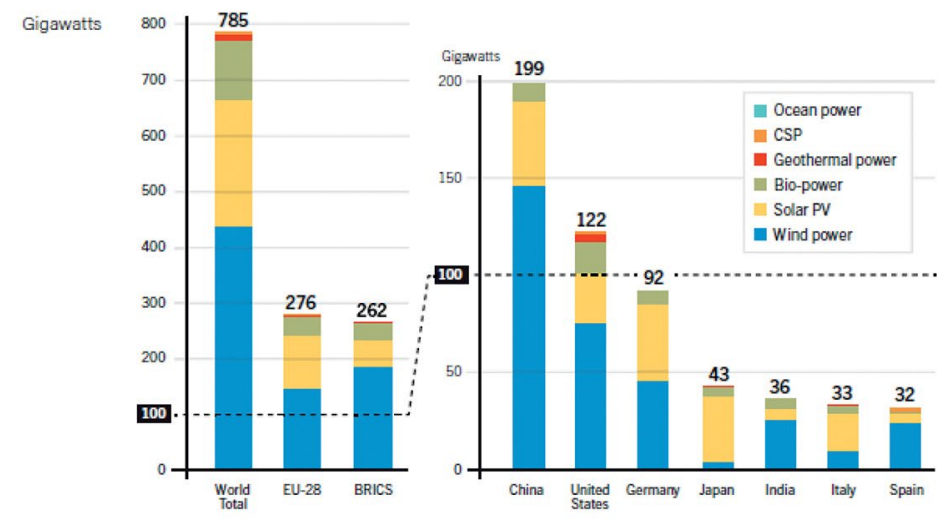

*Not including hydropower (see Reference Table R2 for data including hydropower). The five BRICS countries are Brazil, the Russian Federation, India, China and South Africa.

Figure 14.2 Global and selected countries' renewable power capacity Source: Ren21 (2016).

\section{GLOBAL CAPACITY REACHED $1,064 \mathrm{GW}$}

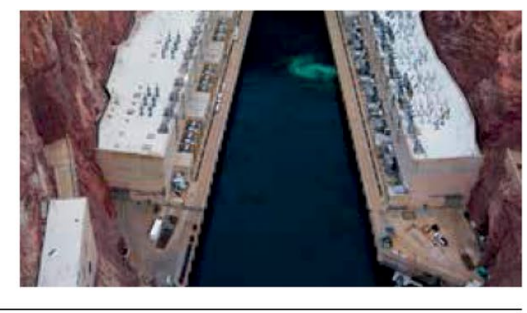

Hydropower Capacity and Additions, Top Six Countries for Capacity Added, 2015
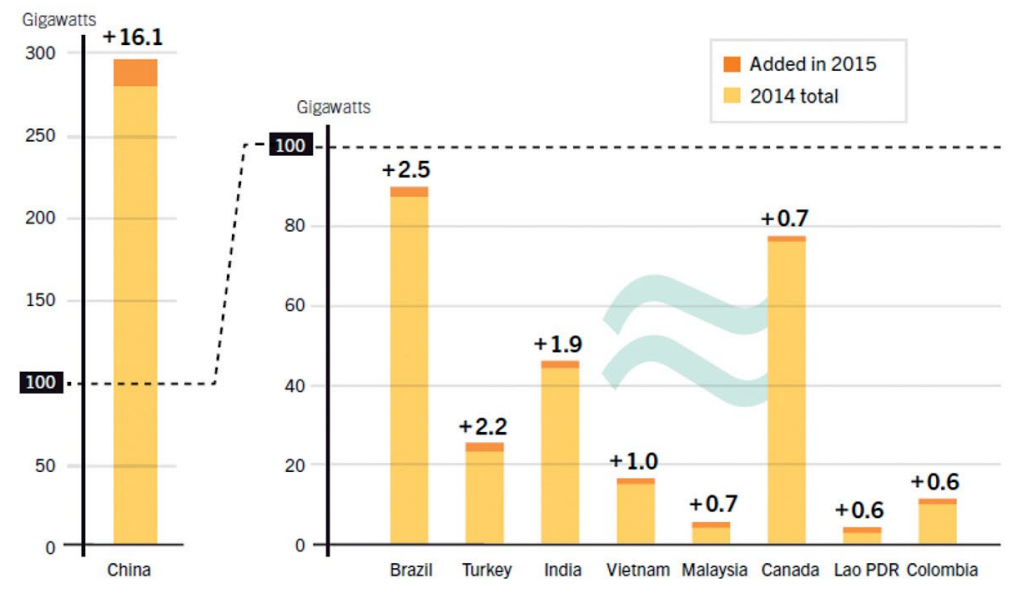

Figure 14.3 Global and selected countries' installed capacity of hydropower Source: Ren21 (2016). 


\section{Progress in 2016}

Based on information from the China Electricity Council (CEC), in 2017, China's national electricity demand reached 5919.8 terawatt-hours (TWh) - 5 per cent more than in the previous year. Of this, electricity demand from primary industries was 107.5 TWh, the growth rate of which was 5.3 per cent. Electricity consumption of secondary industries was 4,210.8 TWh, up by 11.2 per cent year-on-year. Finally, tertiary industries consumed 796.1 TWh of electricity, up 10.8 per cent on 2015.

In 2016, additional installed national power generation capacity reached 120.6 GW, an increase that was 11.23 GW less than the previous year's increase. In 2016, newly installed capacity for thermal power was 48.36 GW (18.42 GW less than the previous year), 34.59 GW for solar power (20.79 GW more than the previous year), 11.74 GW for hydropower (2.01 GW less than the previous year), 18.73 GW for wind power (12.67 GW less than the previous year) and 7.2 GW for nuclear power (1.08 GW more than the previous year).

By the end of 2016, the total installed capacity of power plants with individual capacity of more than $6 \mathrm{MW}$ reached $1,332.11 \mathrm{GW}$. The capacity of grid-connected wind power reached $148.64 \mathrm{GW}$, grid-connected solar power reached $77.42 \mathrm{GW}$ and grid-connected biomass energy reached $12.14 \mathrm{GW}$. Total national renewable energy capacity reached $570.31 \mathrm{GW}$, accounting for 34.7 per cent of China's total power capacity.

Non-fossil fuel energy sources accounted for 36.7 per cent of China's total power capacity by 2016. Specifically, national power generation from renewable energy reached 1,552.6 TWh (or 480 million tonnes of coal equivalent (TCE)), accounting for 25.9 per cent of total national power generation. For power plants with individual capacity of more than $6 \mathrm{MW}$, non-fossil fuel sources generated 1,765.8 TWh (550 million TCE), or 29.5 per cent of the total national power generation from these types of plant.

In 2016, influenced by the benchmark electricity price, solar power capacity increased sharply, with new capacity reaching 34.24 GW-up by 126 per cent yearon-year. In the same year, newly increased capacity for solar PV power stations was 29.98 GW, up by 118 per cent compared with 2015. Newly increased capacity of distributed solar PV power was 4.26 GW, up by 200 per cent compared with 2015; and all together total installed solar PV power capacity was $77.42 \mathrm{GW}$, up by 79 per cent against 2015, and accounting for 4.7 per cent of the total power capacity.

In 2016, total solar power curtailment ${ }^{1}$ reached $74 \mathrm{TWh}$, up by 53 per cent, the rate of curtailment was 11 per cent, down by 0.3 per cent compared with last year.

1 Curtailment means that renewable energy power plants such as solar PV, wind power and hydropower could not make power generation due to grid dispatch, even though there is solar, wind and water flow available for power generation. This normally happens when there is low electricity demand, some power plants have to reduce their output, grid dispatch will decide which power plant has to shut down or lower its output. 
The same year, newly increased capacity for biomass energy was $1.821 \mathrm{GW}$, for agro-forestry biomass it was $0.746 \mathrm{GW}$, for waste-to-energy it was $1.057 \mathrm{GW}$, while for biogas it was $19 \mathrm{MW}$.

Finally, by the end of 2016, total power capacity for biomass energy reached 12.14 GW, agro-forestry reached 6.05 GW and waste-to-energy generation reached 5.74 GW. In 2016, biomass power generation reached 64.7 TWh, up by 20.1 per cent, while forestry residue and agricultural biomass reached 31.6 TWh.

\section{Technological progress}

The rapid development of renewable energy in China has benefited from strong policy support and technological progress (particularly in wind turbines, solar and hydro), which have significantly reduced the costs of these sources.

\section{Wind power}

Technological progress for wind power has been concentrated in changes in turbine size, turbine safety and efficiency. China is a leading producer of wind turbines globally, followed by the European Union (EU) and the United States, with manufacturing distributed among relatively few companies. In 2015, by some estimates, China's Goldwind surpassed Vestas of Denmark to become the world's largest supplier of wind turbines-the first time a Chinese company has held this spot. Almost all of Goldwind's recent growth (and that of other Chinese companies) has come from the domestic market, although Chinese companies are increasingly active in new global markets.

One of the major factors in reducing the cost and increasing the efficiency of wind turbines is increasing the generation capacity per unit. In 2009, the global average capacity per wind turbine unit was 1,599 kilowatts $(\mathrm{kW})$; in China it was $1,360 \mathrm{~kW}$, in the United States 1,500 kW and 2-3 MW in Europe. By following the lead of international wind turbine manufacturers, China's producers have increased their unit capacity and are now catching up with their global competitors. In general, the scaling up of wind power plants and price decreases for materials have seen the cost of wind power plants fall significantly over the past decade. In China, in 2015, there was $30.8 \mathrm{GW}$ of new wind power capacity, with total installed capacity more than 145 GW - a level greater than that of the entire European Union (Ren21 2016).

In 2015, new capacity connected into the national grid was 33 GW and started receiving the FIT premium, with approximately 129 GW considered officially gridconnected. 
Significant growth was expected in anticipation of reduced FIT levels (as of 1 January 2016), but even amid China's economic slowdown, the market surpassed expectations. The market was also driven by the Chinese Government's push to improve energy security and reduce coal consumption due to growing concerns about climate change and air pollution. Wind energy generated $186.3 \mathrm{TWh}$ of electricity in China during 2015, accounting for 3.3 per cent of total electricity generation in the country (up from 2.8 per cent in 2014) (Ren21 2016).

Across China by province, at the end of 2015, Inner Mongolia had 18.7 per cent of China's total wind power capacity, followed by Xinjiang (12.5 per cent), Gansu (9.7 per cent) and Hebei (7.9 per cent). Since the first three of these areas are far from China's major population centres, difficulties continued in the transmission of this power-a challenge compounded by slow growth in electricity demand (0.6 per cent), which led to significant grid curtailment. Curtailment rose in 2015 to an average 15 per cent, up from 8 per cent in 2014, with 33.9 TWh of potential generation kept from the grid. In addition, many turbines sat unused, awaiting completion of long-distance transmission capacity, which is also the reason some wind power companies have begun building farms in the east and south of the country, where average wind speeds are lower and land is more expensive, but where the turbines are closer to the sources of demand, enabling them to be connected to existing grid infrastructure.

Wind power curtailment in China cost the industry an estimated US $\$ 2.77$ billion (RMB18 billion) in 2015. To reduce curtailment, the Chinese Government has urged regions in the northwest of the country to attract more energy-intensive industries and to use wind power for heating (with the added benefit that it can displace coal), among other options. Meanwhile, new transmission capacity is under construction and new pumped-hydro storage facilities are being planned. Curtailment challenges could also be seen in other regions-for example, in the United States, curtailment is down dramatically in Texas following the completion of new transmission lines. In 2015, projects were in the planning stage or underway across the globe to strengthen and expand transmission capacity to efficiently move wind-generated electricity to where it is needed.

In 2015 and 2016, newly installed wind power plants were mainly using 1.5-2 MW units. Larger wind turbines were used mainly in offshore wind farms, with the leading manufacturers in Europe and the United States. Siemens, MHI Vestas and Adwen are working to develop wind turbines with a capacity of $8 \mathrm{MW}$. Chinese companies such as Mingyang are working on units of 6.5-7 MW. 
Based on planning in the 'Made in China 2025-Energy Equipment' strategy announced by the National Development and Reform Commission (NDRC), the Ministry of Industry and Information (MII) and the National Energy Administration (NEA) of China, the focus of future research and development (R\&D) will be $10 \mathrm{MW}$ offshore wind turbines with a centre height of 100 to $200 \mathrm{~m}$.

One challenge for the wind energy sector is low wind speed. In China, 68 per cent of the total land area experiences low wind speeds, concentrated in central-eastern and southern parts of the country, which are also areas of high population density. Low-speed turbines could run with wind speeds of less than 6.5 metres per second $(\mathrm{m} / \mathrm{s})$ or even lower than $5 \mathrm{~m} / \mathrm{s}$. With no such kind of technology in other countries, Chinese manufacturers are leading the way in this technology. Since 2015, there has been a greater focus on developing low-speed turbine technologies, both in China and internationally.

By 2014, China had 25.8 GW of low-speed wind power plants installed and grid connected, and the NEA has approved 74.25 GW for development. The first lowspeed wind power plant in China was constructed in January 2011 in Lai'an county in Anhui province, with installed capacity of $200 \mathrm{MW}$ and average wind speeds of $5.8 \mathrm{~m} / \mathrm{s}$. The plant has 132 wind turbines, each with $1.5 \mathrm{MW}$ of capacity. As with the Lai'an site, most of China's low wind speed areas are hilly or even mountainous and generally complex landscapes, which require more careful site design and higher investment than other areas. At the same time, most low-speed plants are in southeastern China and are therefore close to centres of consumption. Because the utilisation rate for wind turbines is relatively high, there is less problem with curtailment, which is a positive factor for achieving profits from low-speed wind plants. For low-speed plants to be profitable, they need to generate 1,800 to 2,000 equivalent hours per year. While wind turbine blades are becoming longer, it is important to ensure the security and reliability of these power plants.

Plate 14.1 shows the Fenghuangshan wind power plant, developed in 2016, which experiences average wind speeds of less than $6 \mathrm{~m} / \mathrm{s}$. In 2016, power generation from Fenghuangshan was 171.6 gigawatt-hours $(\mathrm{GWh})$, the wind turbine utilisation rate was 98.74 per cent and the average wind speed was less than $6 \mathrm{~m} / \mathrm{s}$. The area is prone to freezing weather and frequent thunderstorms, so the turbine manufacturers had to make technical revisions to respond to these threats. 


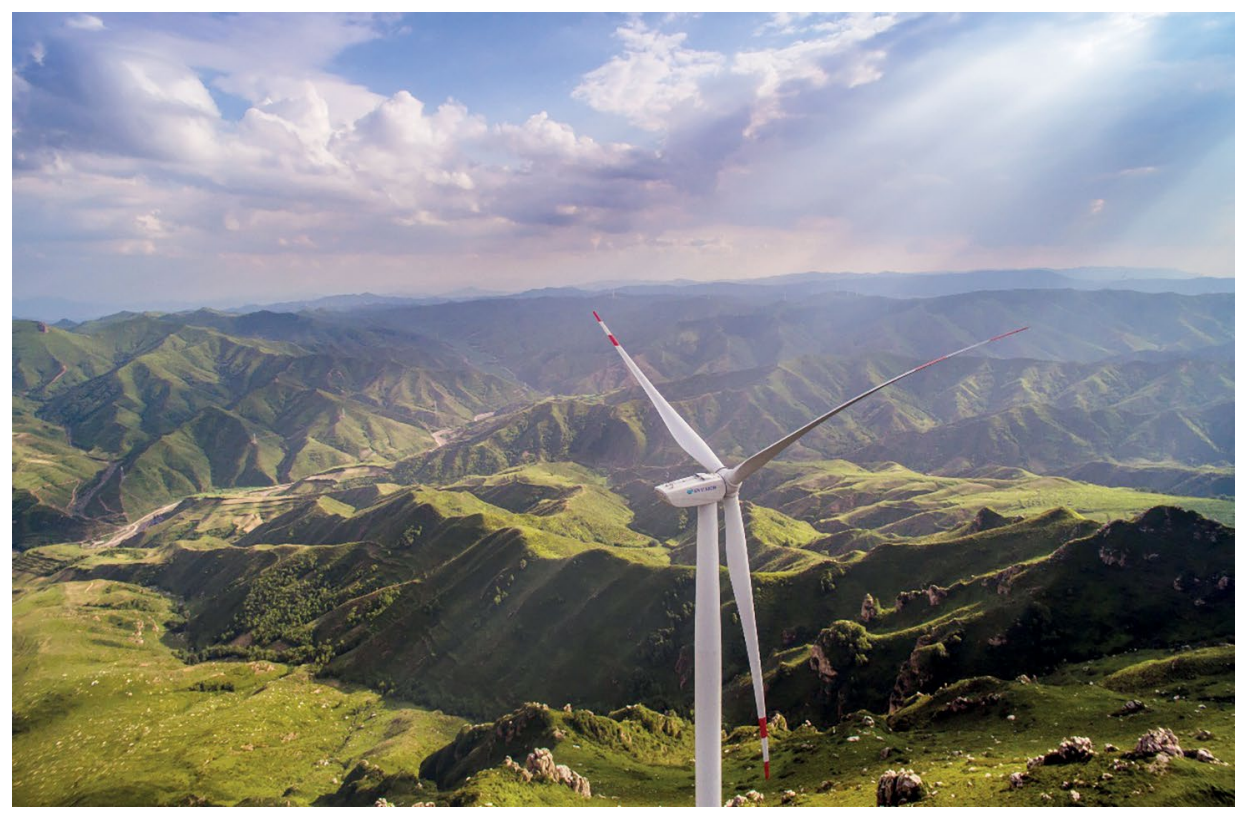

Plate 14.1 Fenghuangshan wind power plant

Source: www.chinadevelopment.com.cn/news/ny/2017/02/1121750.shtml.

China is also home to offshore wind power generation, with offshore installed capacity reaching $1.627 \mathrm{GW}$ in 2016, an increase from just $900 \mathrm{MW}$ in 2015. In 2016, newly installed offshore wind capacity in China accounted for 26.7 per cent of the global total. Also in 2016, China surpassed Denmark to become the third-largest generator of offshore wind power, after the United Kingdom (5.516 GW) and Germany (3.3 GW).

With more than $18,000 \mathrm{~km}$ of coast line, China has potential to generate far greater amounts of offshore wind power than the current 750 GW. Jiangsu, Fujian and Guangdong provinces have the greatest potential for offshore wind power. In 2006, the first offshore wind power plant in China, Rudong, was developed in Zhejiang province.

Development of offshore wind power is growing at a steady pace and is expected to accelerate in the future. China's total installed grid-connected capacity from offshore wind power is forecast to be $30 \mathrm{GW}$ by 2020. Plants in Shanghai, Jiangsu, Zhejiang, Shandong and Fujian provinces are expected to have $25.8 \mathrm{GW}$ of offshore wind power installed by 2020, while in Liaoning, Hebei, Guangdong, Guangxi and Hainan provinces, 9.2 GW of offshore wind energy is planned for 2020. This will mean a total of more than $35 \mathrm{GW}$ of offshore wind power installed by 2020 . 
The unit capacity of offshore wind turbines has increased, from $2 \mathrm{MW}$ to $4 \mathrm{MW}$, $5 \mathrm{MW}$ and even larger units. In 2015, among all installed wind turbines, those with a capacity of $2.5 \mathrm{MW}$ accounted for 18.48 per cent, $3 \mathrm{MW} 17.74$ per cent and 4 MW 34.69 per cent. In 2017, most offshore turbines are 4 to $6 \mathrm{MW}$ units. Offshore turbines must be resistant to corrosion and able to withstand especially high wind speeds - factors that must be incorporated into their design. Engineering modelling and analysis tools are required to lower the costs of offshore facilities and to design the next generation of large-scale turbines optimised for operation in the marine environment.

In May 2014, the total capacity of offshore wind power in China was $565 \mathrm{MW}$, which increased to about $900 \mathrm{MW}$ in 2015. This is, however, less than one-fifth of the earlier target (Figure 14.4). The development of offshore wind power in China has been slower than expected due mainly to the lack of experience of domestic turbine manufacturers. As a result, local developers must use foreign products, with Siemens the largest supplier of offshore wind turbines in China. Other limiting factors are the huge investment needed and the associated risks of offshore development, which discourage private companies.

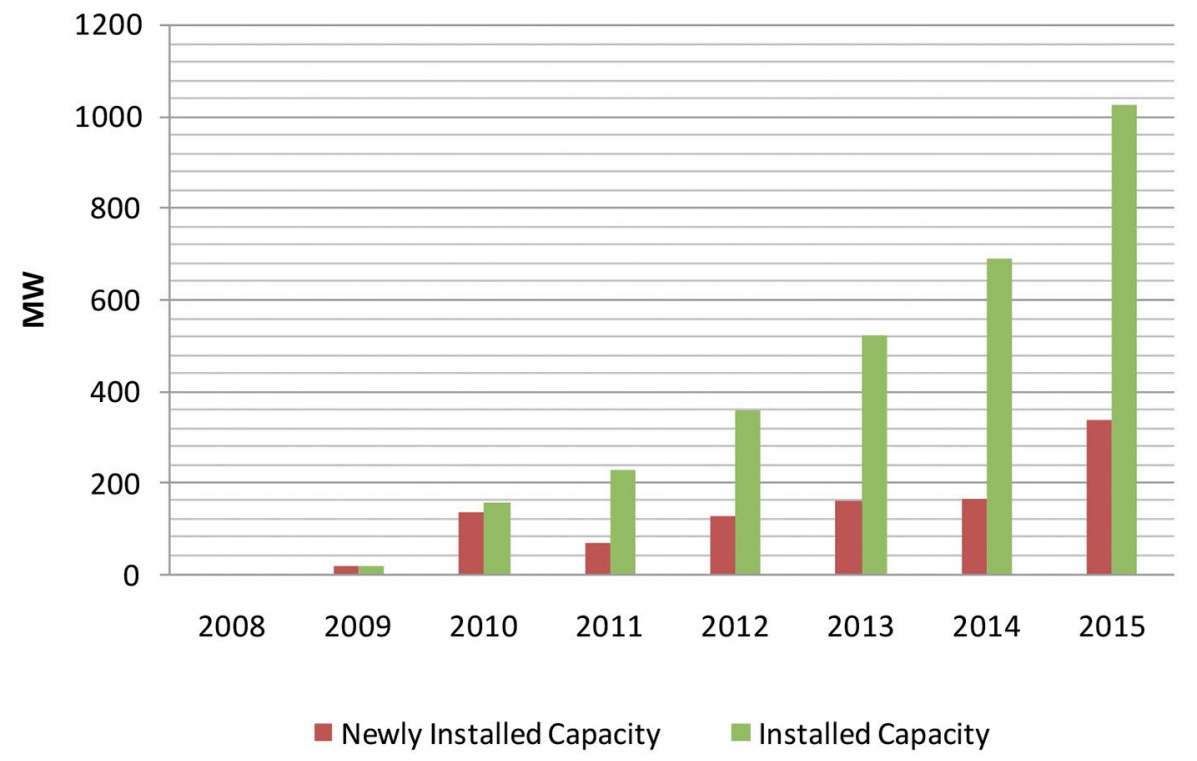

Figure 14.4 Planned and realised installed offshore wind power capacity in China

Source: CEC (2017). 
Another key factor in reducing the cost and extending the scale of wind power generation is improving the onsite installation of wind farms. Chinese companies are now leading the world for wind installation, both onshore and offshore.

Wind power costs in general have shifted over time. Since 2008, there has been a cost reduction of about 35 per cent. In 2016, the average cost for onshore wind power was about RMB7,000 per kilowatt-hours ( $\mathrm{kWh}$ ). For example, for low-speed wind power plants in southern China, the cost for turbines is about RMB4,000/kW, with construction costs of RMB4,000-4,500/kW.

By 2016, the investment cost for establishing wind farms in China was the lowest in the world, at US\$1,050/kW, compared with US $\$ 2,500 / \mathrm{kW}$ in Japan and US\$1,600/ $\mathrm{kW}$ in the United States and Europe. In some areas with good wind conditions and relatively high costs for fossil fuel-fired power plants, wind power already competes on cost with new coal-fired thermal power, including in Australia, Chile, Mexico, New Zealand, Turkey and South Africa.

The cost of wind power generation includes the costs of the turbines, base and installation, connection with the grid and ongoing operation costs. For example, for a low-speed wind farm in southern China, the cost of wind turbines is RMB4,000/ $\mathrm{kW}$, the installation cost is RMB4,000-4,500/kW, operation costs are RMB120$130 / \mathrm{kW}$, labour costs are RMB30/kW with other material costs of RMB70/kW. Such a wind farm could be RMB0.51 to RMB0.54 per kWh levelised cost of electricity (LCOE) by setting a discount rate of 8 per cent, which is lower than the FIT, making the plant profitable. In northern China, however, construction costs are lower, but, due to curtailment, the equivalent utilisation hours will also be lower. If the investment cost is RMB7,500/kW, the LCOE is RMB $0.57 / \mathrm{kWh}$, which is higher than the local FIT, meaning it will be difficult to make the plant profitable.

Future cost reductions for wind power will be found mainly in lowering the overall cost and increasing power output by, for example: 1) increasing the performance and lowering the cost of turbines; 2 ) improving turbine module design and lowering the cost of installation; 3) increasing turbine blade diameter, which increases its efficiency; 4) increasing turbine reliability; and 5) lowering the cost of operation and maintenance. There is some potential to reduce the cost of material, which would lower the cost of turbines. Improved wind forecasting would also increase the reliability, and therefore lower the cost of wind power.

Future wind power development will include increasing the unit capacity of turbines, increasing the efficiency of wind capture and conversion, increasing the quality of components and the efficiency of component transportation and increasing the adaptability of turbines to different environments. 


\section{Solar}

\section{Technological progress}

China is the world's leading country for both solar PV and solar thermal energy, with more than 400 solar PV companies alone. Solar water heating is also used extensively, with a total installed capacity of $290 \mathrm{GWh}$ at the end of 2014, accounting for about 70 per cent of the total global installed solar thermal capacity. In 2016, newly installed solar capacity in China reached 34.59 GW, with total solar grid-connected capacity reaching $77.42 \mathrm{GW}$.

The Chinese Government has continually raised installation targets to increase renewable generation, address the severe pollution problems and promote the domestic manufacturing industry. In 2015, China added an estimated solar PV capacity of $15.2 \mathrm{GW}$ for a total approaching $44 \mathrm{GW}$, overtaking long-time leader Germany to become the top country for cumulative solar PV capacity, with about 19 per cent of the global total. The provinces of Xinjiang (2.1 GW), Inner Mongolia $(1.9 \mathrm{GW})$ and Jiangsu $(1.7 \mathrm{GW})$ were the top markets for the year, with much of this capacity located far from the country's main population centres. However, six provinces in the eastern and central regions each had more than $1 \mathrm{GW}$ of solar PV capacity at 2015. Large-scale solar PV power plants accounted for 86 per cent of total capacity, with the remainder in distributed rooftop systems and other smallscale installations (Ren21 2016).

In support of the development of the solar sector, various solar PV subsidies have been introduced over the past decade. The 'Golden Sun' program was initiated in 2009, providing capital subsidies for solar PV installations through to 2011 on a project-by-project basis. Off-grid (stand-alone) installations receive 70 per cent capital subsidies while grid-connected installations receive 50 per cent subsidies. Qualifying grid-connected installations, however, must have a peak capacity of $300 \mathrm{~kW}$ or larger. There are also program caps, which limit the overall quantity of systems installed; under the terms of the program, installations in any given province are limited to a total of $20 \mathrm{MW}$.

Almost 300 projects have been proposed under the Golden Sun program, totalling $640 \mathrm{MW}$ and entailing about RMB20 billion (US\$2.9 billion) in investment. As a separate part of the program, the Ministries of Finance and Construction are providing subsidies of RMB15 per watt (US\$2.20/W) for grid-connected solar PV and RMB20/W (US\$2.90/W) for building-integrated PV. Eligible installations must be $50 \mathrm{~kW}$ or larger and must utilise solar PV modules achieving minimum efficiency levels (16 per cent for monocrystalline, 14 per cent for polycrystalline and 6 per cent for amorphous). In 2010, the subsidy levels were reduced to RMB13/W (US\$1.90/W) for grid-connected modules and RMB17/W (\$2.50/W) for buildingintegrated modules. 
With parallels to the early development of the wind power industry, the government initiated a new competitive bidding program for solar PV projects in 2009. This program is creating new benchmark tariffs for solar PV (so-called approved price levels) on the basis of competitive bidding. One example was a bidding process in Dunhuang, in Gansu province, in 2009 for two 10 MW projects. Bid prices ranged from aslo was RMB0.69/kWh (US\$0.10/kWh) and resulted in an approved price of RMB1.09/kWh (US\$0.16/kWh). Another approved price was RMB1.15/ $\mathrm{kWh}$ (US\$0.17/kWh) in April 2010 for four projects in Ningxia totalling $40 \mathrm{MW}$.

Finally, at the provincial level, there are also cases of preferential tariffs for solar PV, such as those in Zhejiang and Jiangsu. In Zhejiang in 2009, the tariff was set at a premium of RMB0.70/kWh (US\$0.10/kWh), added to the province average coal power generation price, which was RMB0.46/kWh (US\$0.07/kWh), thus producing a total tariff of RMB1.16/kWh (US\$0.17/kWh). Jiangsu set preferential tariffs significantly higher than Zhejiang, and also established a range of tariffs according to technology type: RMB2.1/kWh (US\$0.31/kWh) for ground-based systems, RMB3.7/kWh (US\$0.54/kWh) for roof top systems and RMB4.3/kWh (US\$0.63/kWh) for building-integrated systems (all prices at 2009 levels). Jiangsu also slated tariffs to decrease progressively, to RMB1.7/kWh for ground-based systems, RMB3/kWh for rooftop systems and RMB3.5/kWh for building-integrated systems in 2010, and to RMB1.4/kWh for ground-based systems, RMB2.4/kWh for rooftop systems and RMB2.9/kWh for building-integrated systems in 2011.

The rapid increase in solar PV capacity in China has, however, caused problems with grid congestion and interconnection delays. Curtailment started to become a serious challenge in 2015, with particularly high rates in the northwestern provinces of Gansu (31 per cent over the year) and Xingjiang Autonomous Region (26 per cent), and a national average of 12 per cent. By year's end, insufficient grid capacity was a significant hurdle for new plants, and investors were growing wary of the sector due to delays in subsidy collection and problems with solar panel quality. To address challenges related to curtailment, the Chinese Government has asked top solar-producing provinces to prioritise transmission of renewable energy, build more transmission capacity and attract more energy-intensive industries to increase local consumption. Against these transmission and curtailment challenges, solar PV generated 2 TWh of electricity in China during 2015-up about 57 per cent from 2014. Chinese companies have also flocked across the border, to Pakistan in particular, where China played an increasingly important role in that country's renewable energy expansion, including in solar PV.

Given the rapid pace of expansion and incentive schemes, many of China's solar product manufacturers experienced low profit margins, excess production capacity and significant debt. For example, Tianwei in 2015 defaulted on an interest payment for a domestic bond and then collapsed, while, in 2017, Yingli required a government 
bailout and, in 2016, Hanergy came under investigation by Hong Kong's Securities and Futures Commission. In general, power production curtailment and delays in subsidy payments have forced some developers in China to sell off projects and halt further development.

The expansion of renewable energy became one of seven categories of business to receive special attention, including loans and tax incentives, under China's five-year plans, especially the Twelfth Five-Year Plan for industry development. The result was the creation of the world's largest solar manufacturing industry-which has become the price leader in most aspects of the global market, beginning with cheaper solar panels. Another result, however, was that China led the creation of a worldwide glut. There were roughly two panels being made for every one ordered by an overseas customer. Between 2008 and 2013, China's fledgling solar-electric panel industry confronted world prices that had dropped by 80 per cent - a stunning achievement even in a fiercely competitive high-tech market.

China's environment is well suited to an advanced solar industry, with some 70 per cent of the most suitable areas concentrated in the western and northern provinces. The annual solar energy received by China's land surface is estimated to be equivalent to 4.9 trillion tonnes of standard coal. Moreover, China has large areas of desert suitable for hosting concentrating solar power (CSP) stations. It has 2.64 million sq $\mathrm{km}$ of arid and desert land, where solar energy resources are abundant. In Xinjiang alone, there are 1.11 million sq $\mathrm{km}$ of desert land.

Prominent projects include the first phase of the Qinghai Delingha Solar Thermal Power Generation Project, which will use Bright Source Energy's proven solar tower technology to produce clean, reliable solar electricity for more than 452,000 homes. Located in Qinghai province in northwestern China, the Delingha project will have six $135 \mathrm{MW}$ CSP tower plants, with the first phase including two $135 \mathrm{MW}$ solar plants with up to 3.5 hours of thermal energy storage. It is expected construction will be completed in 2017 .

Meanwhile, China is home to the world's largest solar park, which the US National Aeronautics and Space Administration (NASA) has published satellite images of (Plate 14.2). Also in Qinghai province, the plant has a startling scale of some 850 MW. Landsat 8 satellite images taken in January 2017 capture the four million solar panels installed at the site, which cover an area equivalent in size to Macau. 


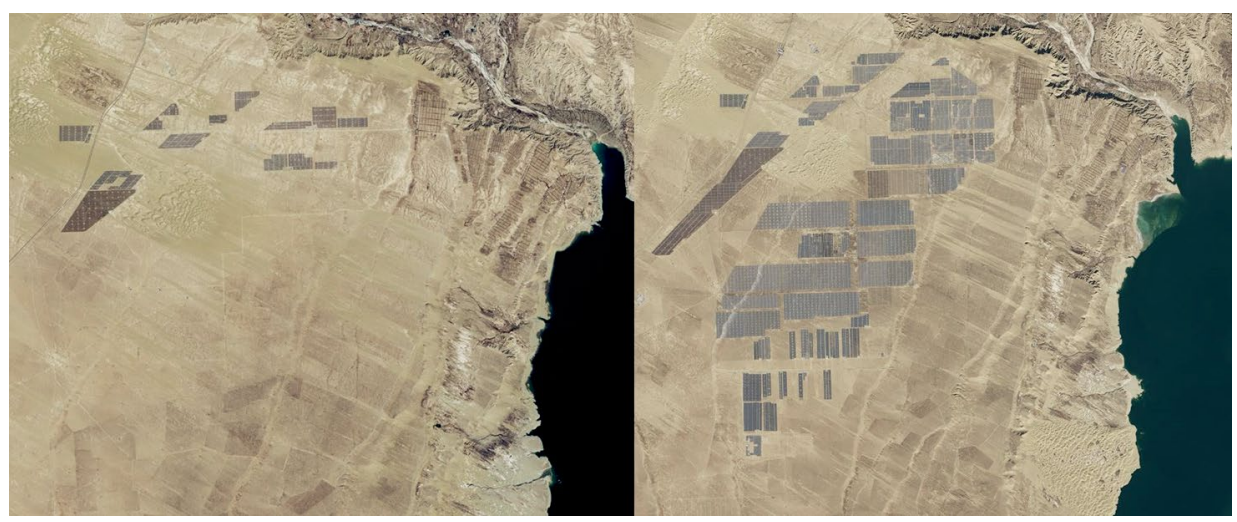

Plate 14.2 Satellite image of Delingha solar PV project in Qinghai province Source: NASA image. Available from: www.pv-magazine.com/2017/0202/nasa-images-showstunning-progress-of-chinas-vast-850-mw-longyangxia-solar-park/.

Plate 14.2 comprises two images: the view on the left is from April 2013, while the image on the right shows how the plant looked in February 2017. The Delingha plant became the largest solar power plant in the world, surpassing the $648 \mathrm{MW}$ Kamuthi Solar Power Project in Tamil Nadu, India. China is also currently constructing an even larger installation, in the Ningxia autonomous region, with a capacity of $2 \mathrm{GW}$.

CSP is still in the early stages of commercial application in China. It is closely related to traditional methods of power generation, which helps to lower the risk of technological development. China has established ambitious goals for CSP deployment and, despite a slow start, it remains a particularly exciting concept with thermal storage applications, especially given the country's strong commitment to diversifying and decarbonising its energy mix.

Solar thermal plants can harness solar energy by using molten salt as a heat-transfer medium, which improves the efficiency of the power generation system by providing higher temperatures and a more stable medium. Old CSP systems used oil or water as the medium, but oil could not reach high temperatures and, while water was easy to turn into steam, it had to be contained at high pressure. China's first molten salt solar thermal power plant has started to send electricity to the grid. The Tianjin Binhai Concentrating Solar Power Investment Co. Ltd said its $50 \mathrm{MW}$ molten salt trough project in Akesai in northwest China's Gansu province demonstrates the maturity of the commercial development of solar thermal technology. The company will carry out large-scale production with the technology in 2018, when it is scheduled to produce facilities with $200 \mathrm{MW}$ of annual solar power output. The Akesai plant was among 20 demonstration solar thermal plants listed for construction by China's NEA in 2016 as the government eyes off the potential of renewable energy. 
The Twelfth Five-Year Plan (2011-15) called for the installation of 1 GW by 2015 and 3 GW by 2020 of CSP plants. Plants either being planned or under construction include the following:

1. $1 \mathrm{MW}$ Badaling Pilot Project-a collaboration between the Institute of Electrical Engineering (IEE) and the Chinese Academy of Sciences (CAS).

2. $12 \mathrm{MW}$ (short-term)/300 MW (long-term) collaboration between Xinjiang Qingsong Building Materials and Chemicals (Group) Co. and Guodian Xinjiang Company.

3. $50 \mathrm{MW}$ project in Tibet by Huaneng Tibet Company.

4. $100 \mathrm{MW}$ project in Sichuan's Ngawa Tibetan and Qiang Autonomous Prefecture (Aba) by Tianwei New Energy.

5. $50 \mathrm{MW}$ project (to be determined) by China Huadian Corporation.

6. $100 \mathrm{MW}$ project in Golmud by GD ENERGY.

7. $100 \mathrm{MW}$ project in Ningxia by Beijing Control Technology Co. Ltd.

8. $100 \mathrm{MW}$ project (to be determined) by Avic Xi'an Aero-Engine (Group) Ltd.

9. $100 \mathrm{MW}$ project (to be determined) by Guangdong Kangda.

10. $100 \mathrm{MW}$ project in Gansu by SETC Tianjin.

11. 1,000 MW project in Qinghai by Lion International Investment Ltd.

12. 2,000 MW project in Shaanxi by Shandong PenglaiDianli and eSolar.

CSP is planned to reach $5 \mathrm{GW}$ of electricity generation by 2020 , which is more than the total global installed capacity of CSP in 2015. Construction of the $50 \mathrm{MW}$ Qinghai Delingha facility commenced in late 2015. The facility, which will be the country's first commercial CSP plant, is expected to come online in 2017. Additional facilities totalling several hundred megawatts are in various stages of construction, although timelines for completion remain unclear.

Another utilisation of solar energy is for water heating. China dominates the global market for solar water heating, accounting for more than 70 per cent of the world total. China was the largest market by far in 2015, with gross additions of $30.45 \mathrm{GW}$ thermal (GWth) (43.5 million sq $\mathrm{m}$ of panel area) - 21 times more capacity than was added in second-placed Turkey. At year's end, China's cumulative capacity in operation was an estimated 309.4 GWth, or about 71 per cent of the world's total. China's market contracted for the second consecutive year-falling 17 per cent in 2015 after an 18 per cent drop in 2014_due to the slowdown in the construction industry and the weaker national economy.

Solar water heaters utilise various technologies, such as vacuum tubes, heat pipe solar tubes, flat plate collectors and solar cylinders. Vacuum tubes continued to dominate the Chinese market in 2015, accounting for 87 per cent of added capacity; however, flat plate collectors were still popular, especially for roof and facade integration in 
urban areas. Heat pipe solar tubes are the most advanced option, but also the most expensive. In China, solar thermal systems for use in multi-family houses and in the tourism and public sectors accounted for 61 per cent of the newly installed collector area in 2015 .

\section{Producers and cost changes}

China has been the world's largest manufacturer of solar panels since 2008 and, since 2011, has produced the majority of the world's PV systems on an annualised basis. Industry projections estimate that, by the end of 2017, China will have enough manufacturing capacity to produce $51 \mathrm{GW}$ of photovoltaics a year. Domestic demand in China was around $34 \mathrm{GW}$ in 2016 - more than twice as much as global production in 2010, of $24 \mathrm{GW}$.

The industry is dominated by several major manufacturers, including CHINT Group Corporation, JA Solar Holdings, Jinniu Energy, Suntech Power, Yingli, China Sunergy and Hanwha Solar One. Several manufacturers are confronting challenges of large debts.

Within 10 years, the cost of solar PV panels in China dropped significantly, from above RMB50 per watt to RMB4/W, while system costs reduced from RMB60/W to $\mathrm{RMB} / \mathrm{W}$, a decrease rate of more than 85 per cent. With the reduction in investment costs, the cost of solar PV power generation also reduced, by 76 per cent, which increased market competitiveness.

The main driver of such cost reductions is the scaling up of solar PV power via technological innovation. Rapid increases in the market boost manufacturing volumes while lowering production costs. Technological innovation created new products that were more efficient to manufacture and delivered higher efficiency of power generation.

\section{Hydro}

\section{Overview}

Hydropower in China is still the cheapest source of power generation, and hydroelectricity is the most cost-effective and stable form of renewable energy. This allows developers to install hydro-electric power without the need for considerable FITs. Hydropower also benefits from flexibility, with plants able to adjust their output quickly in response to changing energy demands over certain periods.

From 2010 to the end of 2016, newly installed capacity for hydropower in China reached 103.48 GW, following year-on-year growth of 8.1 per cent. Of this, newly installed large hydropower accounted for $80.76 \mathrm{GW}$, small hydro for 16.6 GW and pumped storage hydro for 6.12 GW. Total capacity for hydropower reached 
319.54 GW, accounting for 27 per cent of the global total. Of that total, large hydro contributed 221.51 GW, small hydro $75 \mathrm{GW}$ and pumped storage hydro 23.03 GW. Hydropower generation in China produces 1,100 TWh, accounting for 19.4 per cent of total national power output and 73.7 per cent of non-fossil fuel power generation. Of the 10 largest hydropower stations in the world, five are in China. Half of all hydropower units with capacity above $700 \mathrm{MW}$ globally are operated by China Three Gorges Corporation.

Moreover, many additional hydro projects are under construction in China (Table 14.1). Newly started construction capacity is 20.9 GW in 2015, which is the highest level in history.

Table 14.1 Hydropower projects under construction in China

\begin{tabular}{|l|l|l|}
\hline Type & River/grid & Power station \\
\hline \multirow{5}{*}{ Regular hydropower } & Jinsha River & $\begin{array}{l}\text { Wudongde, Liyuan, Suwalong, Ahai, Ludila, } \\
\text { Longkaikou, Guanyinyan }\end{array}$ \\
\cline { 2 - 3 } & Yalongjiang River & Lianghekou, Yangfanggou \\
\cline { 2 - 3 } & Daduhe River & $\begin{array}{l}\text { Shuangjiangkou, Houziyan, Huangjinping, Angu, } \\
\text { Zhentouba, Shaping second level }\end{array}$ \\
\cline { 2 - 3 } & Yellow River & Liujiaxia(extension), Huangfeng \\
\cline { 2 - 3 } & Other rivers & $\begin{array}{l}\text { Mamaya, Fengman(rebuild), Xiaoxuan, Lizhou, } \\
\text { Kajiwa, Duobu }\end{array}$ \\
\hline hydropower & North China Grid & Fengning, Wendeng, Yimeng \\
\cline { 2 - 3 } & East China Grid & Jixi, Jinsai, Chuanglongshan \\
\cline { 2 - 3 } & Middle China Grid & Tianchi, Panlong \\
\cline { 2 - 3 } & Northeast China Grid & Dunhua, Huanggou \\
\cline { 2 - 3 } & Southern China Grid & Qiongzhong, Shenzhen, Meizhou, Yangjiang \\
\hline
\end{tabular}

Source: NDRC (2007).

Although hydropower is an efficient type of renewable energy from a production and FIT perspective, it also presents some challenges, including long development periods, associated social displacement and environmental concerns, as well as the increasing difficulty of accessing potential development sites. These factors suggest that China's investment in hydropower will decline after 2020. The social and environmental consequences of large hydropower installations present another challenge. Almost 1.5 million people were displaced for the construction of the Three Gorges Dam. Migration is becoming a key issue in the development of hydropower and will complicate future development of the sector.

The major international providers of hydropower equipment are GE (United States), Andritz Hydro (Austria) and Voith Hydro (Germany), each with roughly equal market share. Together, they account for about half of the global industry. Other notable manufacturers include Harbin (China), Dongfang (China) and Power Machines (Russian Federation). 
A slowdown in the development of hydropower in China and market saturation are inspiring Chinese corporations to increase their involvement in hydropower projects around the world. Their involvement has included both construction and operation, with a particular focus on Africa, South Asia and South America. In early 2016, China Three Gorges Corporation acquired two hydropower plants in Brazil, becoming that country's second-largest private power producer.

Based on the newly published Thirteenth Five-Year Plan for hydropower development in China, the target for installed hydropower capacity is $380 \mathrm{GW}$, of which 340 $\mathrm{GW}$ is normal hydropower and $40 \mathrm{GW}$ is pumped hydro storage. Annual power generation will be $1,250 \mathrm{TWh}$, accounting for more than 50 per cent of total nonfossil fuel power generation.

Total hydropower resources available for development are $660 \mathrm{GW}$, with annual power generation of about 3,000 TWh. There is uneven distribution, with 70 per cent of hydropower resources in the south-west of the country.

In terms of technological developments, China is the world leader in developing hydropower, from planning, design and construction to equipment manufacture, operation and maintenance.

In recent years, major technological progress in hydropower has included construction of a 300-m-high arch dam in complex geological conditions, a super high core rockfill dam with gravel soil, a 35-m-wide underground hydropower house and multiple deep-ground water headrace tunnels. The $800 \mathrm{MW}$ Francis-type hydropower turbine and $350 \mathrm{MW}$ pumped hydro power units with $500 \mathrm{~m}$ head could be manufactured in China. Constructed in the past few years were the world's highest concrete double-curvature arch dam (Jinping First-Grade Hydropower Station), deep-long tunnel hydropower (Jinping Second-Grade Hydropower Station), the world's third-largest hydropower station (Luoxidu Hydropower Station) and a hydropower station in complex geological conditions (Dagangshan Hydropower Station).

Newly announced hydropower development plans for China focus on development of a grid and transmission system because of the uneven distribution of hydropower resources throughout the country. Based on current planning, more than $100 \mathrm{GW}$ of hydropower will ultimately be transmitted from the west of the country to the east.

There are nonetheless challenges confronting the hydropower sector in China. Environmental issues are receiving increased public attention, making it more difficult to implement new projects. It is becoming more difficult to forcibly relocate populations away from potential hydro project areas. New hydro projects 
are therefore tending to move towards remote regions and areas of low economic development. In such areas, hydropower is seen as a means of developing the local economy, and low population density also reduces migration costs.

\section{Biomass}

Biomass energy refers to energy from agricultural residues and waste, forestry products and waste, bioethanol, biodiesel and biogas from animal husbandry and municipal waste. China has large biomass energy potential. For a long time, the government promoted traditional biomass utilisation including of straw and firewood for energy generation in rural areas. High-efficiency biomass stoves, biomass-heated beds and biomass digesters were supported by rural energy policies for decades. Policies for modern biomass energy utilisation were initiated from 2005. By 2010, the total installed capacity of biomass power generation in China had reached 5.5 GW. The annual utilisation rate of densified biofuels had been as high as 1 million tonnes and that of biogas 19 billion cubic metres; the utilisation rate of ethanol fuel from non-grain raw materials reached 2 million tonnes and that of biodiesel reached 200,000 tonnes (State Council 2011).

Since 1995, China has included biomass energy in its national five-year plans. In the Ninth Five-Year Plan (1996-2000), the development of highly efficient anaerobic technology for treating high-concentration organic wastewater and urban garbage was listed as a key science and technology program. During the Tenth Five-Year Plan (2001-05), development planning for the agricultural biomass energy industry was introduced. Each plan since the Eleventh Five-Year Plan has contained special planning for the biomass energy industry.

A scheme for the comprehensive utilisation of crop straws during the Twelfth FiveYear Plan (2011-15), issued in 2011, points to further development of output generation from this source. It was planned to achieve a straw utilisation rate of more than 80 per cent and straw energy utilisation rate of 13 per cent by 2015 . Twelfth Five-Year Plan targets for renewable energy development and biomass energy development, issued in 2012, stipulated that, by 2015, the annual utilisation rate of biomass energy would exceed 50 million TCE. When total installed capacity of biomass power generation reaches $13 \mathrm{GW}$ and related annual power generation is up to about $78 \mathrm{TWh}$, the annual biomass supply will be up to 22 billion $\mathrm{cu} \mathrm{m}$, densified biofuel will be 10 million tonnes and biological liquid fuel 5 million tonnes. Planning for biomass energy in the Thirteenth Five-Year Plan is under way.

On the one hand, the development and utilisation of biomass energy offer potential to replace thermal energy sources and therefore better protect the environment. On the other hand, the costs of development and utilisation are so far unable to compete with those of traditional energy sources. This has led the Chinese 
Government to adopt a series of incentive measures for enterprises and users to ease this cost burden and directly subsidise the development and utilisation of biomass energy. The main measures include front-end incentives to encourage development of the biomass energy production chain and market back-end incentives to stimulate sales and use, as well as some indirect incentives to promote the development of the whole industry.

In China, biopower capacity reached $10.3 \mathrm{GW}$ in 2015, an increase of $0.8 \mathrm{GW}$ over the previous year. Generation was up 16 per cent compared with 2014, to around 48.3 TWh. The Twelfth Five-Year Plan set a target of 13 GW by 2015, but actual installed capacity for biomass power generation has not reached that target. Factors that have restricted progress include high prices for feedstock, poor coordination among projects and technical operating difficulties.

China, the world's third-largest ethanol producer, produced an estimated 2.8 billion litres in 2015-a 14 per cent decrease. China increased ethanol imports during that year but added no new production capacity, in part because of a moratorium on maize-based ethanol production. Asia's other major producer, Thailand, saw its ethanol production rise by 10 per cent, from 1.1 billion litres in 2014 to 1.2 billion litres in 2015 . China's biodiesel production is estimated to have increased substantially_by an estimated 24 per cent- to 0.35 billion litres in 2015 (Ren21 2016).

Based on the Thirteenth Five-Year Plan's goals for renewable energy, the target for 2020 for total installed capacity of biomass power generation is $30 \mathrm{GW}$; the annual utilisation rate of densified biofuel will be 50 million tonnes, biogas 44 billion cu m, non-grain raw material fuel ethanol 10 million tonnes and biodiesel 2 million tonnes.

\section{Other renewables}

The countries with the largest direct-use geothermal power capacity are China (6.1 GW), Turkey (2.9 GW), Japan (2.1 GW), Iceland (2 GW), India (1 GW), Hungary $(0.9 \mathrm{GW})$, Italy $(0.8 \mathrm{GW})$ and the United States $(0.6 \mathrm{GW})$. In line with installed capacity, China utilised the most direct geothermal heat $(20.6 \mathrm{TWh})$.

China is also developing ocean-energy technologies_-both tidal and wave energy. In 2015, there were 10.7 MW of capacity installed, including several projects in development. The Jiangxia tidal power plant was upgraded in 2015, from 3.9 MW to 4.1 MW. Among new development projects is the $100 \mathrm{~kW}$ Sharp Eagle wave energy converter, which was deployed in 2015. China's experience to date is that the country's current tidal technologies exhibit significantly lower cost structures than its wave energy projects, but all are limited by immature technology and lack of experience and supporting infrastructure. 


\section{Policy development}

Development of new and clean sources of renewable energy in China is a key strategic measure for fostering emerging industries of national importance. It is also promoted as part of national action towards protection of the environment, responses to climate change and achievement of sustainable development. China worked to increase the shares of non-fossil fuels in primary energy consumption to 11.4 per cent and installed generation capacity to 20 per cent by the end of 2030 .

Against the background of a global energy crisis, local air pollution and climate change, the development of renewable energy utilisation technology has important practical and long-term significance for replacing fossil fuels and realising the sustainable development of humanity. China's energy security has become an increasingly prominent issue, environmental constraints have increased and the situation for energy savings and emission reductions is grim. In this context, the government has prioritised adjustment of China's energy structure and development of alternative, green, clean, low-carbon renewable energy sources. Biomass energy — with plentiful resources and stable supply — can substitute for coal, oil and gas in huge quantities. It can also significantly reduce pollution and achieve near-zero emissions of carbon dioxide. In recent years, therefore, governments at all levels in China have increased their focus on renewable energy and introduced a series of policies and measures for the sector.

The basic framework of China's renewable energy development policies include the Renewable Energy Law, a medium- and long-term development plan for renewable energy and each five-year plan as the short-term plan to attract producers and users to participate in the development and utilisation of renewable energy through the establishment of a series of effective incentive mechanisms.

\section{Legal basis}

The Renewable Energy Law of the People's Republic of China was issued in 2005 and formally implemented on 1 January 2006. This is the first energy law in China and indicates the importance the Chinese Government has placed on renewable energy.

The Renewable Energy Law was revised at the end of 2009 and the new edition was implemented on 1 April 2010. The amendment established the Renewable Energy Development Fund to be collected by additional charging from grid on electricity, to support the development of renewable energy. 


\section{Target system}

The Chinese Government's plan for medium- and long-term renewable energy development aimed to increase renewable energy's share of total energy consumption to 10 per cent in 2010 (from 7.5 per cent in 2005) and to 16 per cent by 2020. The plan treats wind power generation as a key renewable energy source and sets medium and long-term wind power development goals through to 2020 (Table 14.2).

The plan places emphasis on the development of renewable energy, including wind, solar, hydro, biomass, biogas, densified biofuel and biological liquid fuel. Table 14.2 shows the targets set in the plan according to the requirements of China's economic and social development and biomass energy utilisation technology.

Table 14.2 Renewable energy development targets for China

\begin{tabular}{|l|c|c|c|}
\hline & 2005 & 2010 & 2020 \\
\hline $\begin{array}{l}\text { Renewable energy's share of } \\
\text { total energy consumption }\end{array}$ & $7.2 \%$ & $10 \%$ & $16 \%$ \\
\hline $\begin{array}{l}\text { Annual renewable energy } \\
\text { consumption }\end{array}$ & $160 \mathrm{~m} \mathrm{TCE}$ & $270 \mathrm{~m} \mathrm{TCE}$ & $530 \mathrm{~m} \mathrm{TCE}$ \\
\hline $\begin{array}{l}\text { Renewable energy's share } \\
\text { (excluding hydropower) of total } \\
\text { power generation }\end{array}$ & - & $1 \%$ & $3 \%$ \\
\hline $\begin{array}{l}\text { Hydropower generation } \\
\text { capacity }\end{array}$ & $117 \mathrm{GW}$ & $180 \mathrm{GW}$ & $300 \mathrm{GW}$ \\
\hline $\begin{array}{l}\text { Wind power generation } \\
\text { capacity }\end{array}$ & $1.26 \mathrm{GW}$ & $5 \mathrm{GW}$ & $30 \mathrm{GW}$ \\
\hline $\begin{array}{l}\text { Biomass power generation } \\
\text { capacity }\end{array}$ & $2 \mathrm{GW}$ & $5.5 \mathrm{GW}$ & $30 \mathrm{GW}$ \\
\hline $\begin{array}{l}\text { Annual methane gas } \\
\text { consumption }\end{array}$ & $70 \mathrm{~mW}$ & $19 \mathrm{~b} \mathrm{cu} \mathrm{m}$ & $40 \mathrm{~b} \mathrm{cu} \mathrm{m}$ \\
\hline $\begin{array}{l}\text { Photovoltaic power generation } \\
\text { capacity }\end{array}$ & $1.02 \mathrm{~m} \mathrm{t}$ & $2 \mathrm{~m} \mathrm{t}$ & $300 \mathrm{~mW}$ \\
\hline $\begin{array}{l}\text { Solar water heaters' heat } \\
\text { collection area }\end{array}$ & $\begin{array}{l}\text { Annual bioethanol } \\
\text { consumption }\end{array}$ & $150 \mathrm{~b} \mathrm{sq} \mathrm{m}$ & $\mathrm{m} \mathrm{t}$ \\
\hline
\end{tabular}

TCE $=$ tonnes of coal equivalent

$\mathrm{m}=$ million

$\mathrm{b}=$ billion

Source: NDRC (2007). 
With the progress of renewable energy technology and strong government policies, renewable energy development in China, especially wind and solar power generation, has always exceeded its targets, meaning these targets undergo constant revision. Table 14.3 presents the revised targets.

Table 14.3 Revised targets for renewable energy in China

\begin{tabular}{|l|l|}
\hline Year & Target \\
\hline 2009 & $80 \mathrm{GW}$ of wind by 2020 \\
\hline 2010 & $150 \mathrm{GW}$ of wind, $20 \mathrm{GW}$ of solar by 2020 \\
\hline 2013 & Twelfth Five-Year Plan: $20 \mathrm{GW}$ of solar PV, $150 \mathrm{GW}$ of wind by 2015 \\
\hline 2013 & $35 \mathrm{GW}$ of solar PV by 2015 \\
\hline 2016 & $250 \mathrm{GW}$ of wind, $100 \mathrm{GW}$ of solar by 2020 \\
\hline
\end{tabular}

Source: Author.

The 2005 Renewable Energy Law authorised feed-in tariffs for wind power based on 'government guided' prices, which have evolved year-by-year with competitive bidding for wind power capacity, resulting in standardised or 'approved' prices, generally on a province-by-province basis.

According to Article 14 of the Renewable Energy Law, grid enterprises (State Grid) should sign FIT agreements with renewable energy power plant companies that have received permission from the government.

FITs were implemented in China as early as 2003 in support of the deployment of wind power. At first, the tariff amount was determined on a case-by-case basis through bidding or negotiation. However, this arrangement created intense competition among large state-owned renewable power generators, which issued speculative bids that were often insufficient to actually implement the project. This practice was considered harmful to the long-term sustainability of the wind power industry.

In response, the NDRC set baseline prices for wind tariffs in August 2009. The minimum tariff ranged from RMB0.51/kWh to RMB0.61/kWh, depending on the location of the wind farm, with four classes of wind resource ranking. ${ }^{2}$ In 2011, the NDRC set the national solar FIT at RMB1/kWh for projects started in 2011 or later. To support the FITs, the NDRC established a renewable electricity surcharge in 2006, of RMB0.001/kWh. The surcharge was increased to RMB0.004/ $\mathrm{kWh}$ in 2009 and again, to RMB0.008/kWh, in 2011, to support the increasing demand for FITs following rapid growth of renewable energy. Despite the eightfold rate hike, the surcharge remains low by international standards: with an average residential electricity price of $\mathrm{RMB} 0.52 / \mathrm{kWh}$, the surcharge is 1.5 per cent of

2 In order to process benchmark prices for wind power generation, four classes of wind power generation areas were defined based on the wind resource, they are Class I to IV. 
the total electricity price. In comparison, Germany's renewable energy surcharge reached $€ 0.053 / \mathrm{kWh}(\mathrm{RMB} 0.43 / \mathrm{kWh})$ in 2013 , or 20 per cent of the total electricity price. China's low renewable electricity surcharge is important for the sustainable development of renewable energy because it leaves sufficient room for future expansion of FITs.

Finally, there are new provincial-level solar PV preferential tariffs. Zhejiang and Jiangsu have established province-wide preferential tariffs for solar PV. In Zhejiang, the tariff was set as a premium of RMB0.70/kWh (US $\$ 0.10 / \mathrm{kWh}$ ) added to the province-average coal power generation price, which was RMB0.46/kWh in 2009 (US\$0.07/kWh), thus producing a total tariff of RMB1.16/kWh (US\$0.17/kWh). Jiangsu set preferential tariffs significantly higher than Zhejiang, and also established a range of tariffs depending on technology type: RMB2.1/kWh (US $\$ 0.31 / \mathrm{kWh}$ ) for ground-based systems, RMB3.7/kWh (US\$0.54/kWh) for rooftop and RMB4.3/ $\mathrm{kWh}$ (US\$0.63/kWh) for building-integrated systems (all prices at 2009 levels). Jiangsu also slated its tariffs to decrease progressively, to RMB1.7/kWh for groundbased systems, RMB3/kWh for rooftop and RMB3.5/kWh for building-integrated systems in 2010, and to RMB1.4/kWh for ground-based systems, RMB2.4/kWh for rooftop and RMB2.9/kWh for building-integrated systems in 2011. These preferential tariffs were not, however, considered nationally 'approved' prices, which means the money to cover them will have to come from the provincial rather than the national budget.

During 2012-15, it was announced that all new solar projects without state subsidies would be included in Jiangsu's PV subsidy policy, based on the national uniform electricity price. The policy would be implemented for the integrated operation of ground-based, rooftop and building-integrated systems with the electricity price of RMB1.2/kWh in 2014 and RMB1.15/kWh in 2015.

In December 2016, the NDRC released the lower FIT for new projects in 2017. For wind power, the tariffs are 15 per cent, 10 per cent, 9 per cent and 5 per cent lower for the four classes of wind resource rankings, giving rates of RMB0.40/ kWh, RMB0.45/kWh, RMB0.49/kWh andRMB0.57/kWh, respectively. For solar power, the FIT reductions are 19 per cent, 15 per cent and 13 per cent for the three solar resource rankings, ${ }^{3}$ to rates of $\mathrm{RMB} 0.65 / \mathrm{kWh}, \mathrm{RMB} 0.75 / \mathrm{kWh}$ and RMB0.85/kWh, respectively. The subsidy for distributed solar power remains at $\mathrm{RMB} 0.42 / \mathrm{kWh}$. The FITs for offshore wind and tidal zone wind power also remain unchanged, at RMB0.85/kWh and RMB0.75/kWh, respectively.

3 Similar to the wind resource ranking, there are also three classes of solar power generation regions based on the resource of solar energy, from Class I to III, to decide the benchmark prices for solar power generation. 
Based on a recent announcement by the NEA, power companies will be required to source more than 15 per cent of their power from renewable energy generation, not including large hydro. This is another signal to promote further renewable energy development.

\section{Future development of renewable energy}

The goal of keeping the rise in global temperature to $2^{\circ} \mathrm{C}$ and China's own air quality targets are powerful push factors for the transition of energy systems. Based on the study by the Integrated Policy Assessment Model for China (IPAC) modelling team, energy transition in China alone could support the global climate change target, concurrent with improving air quality. Figure 14.5 presents primary energy demand under the global $2^{\circ} \mathrm{C}$ target.

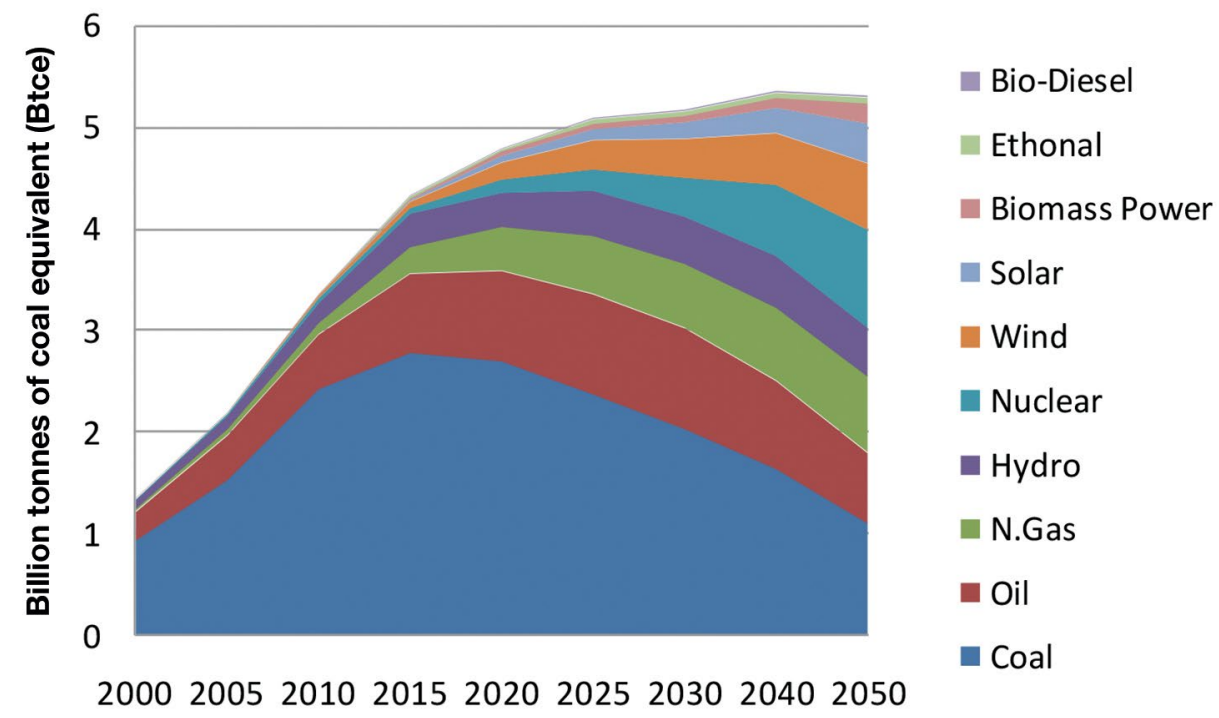

Figure 14.5 Primary energy demand in China under the global $2^{\circ} \mathrm{C}$ target Source: Jiang et al. (2013).

By 2050, renewable energy will account for 33.8 per cent of total primary energy demand in China-an increase from 11.4 per cent in 2015. Installed capacity of renewable energy will increase to $289 \mathrm{GW}$ by 2050, while power generation from renewable energy will be 571 TWh by 2050 (Figures 14.6 and 14.7). 
China's New Sources of Economic Growth (II)

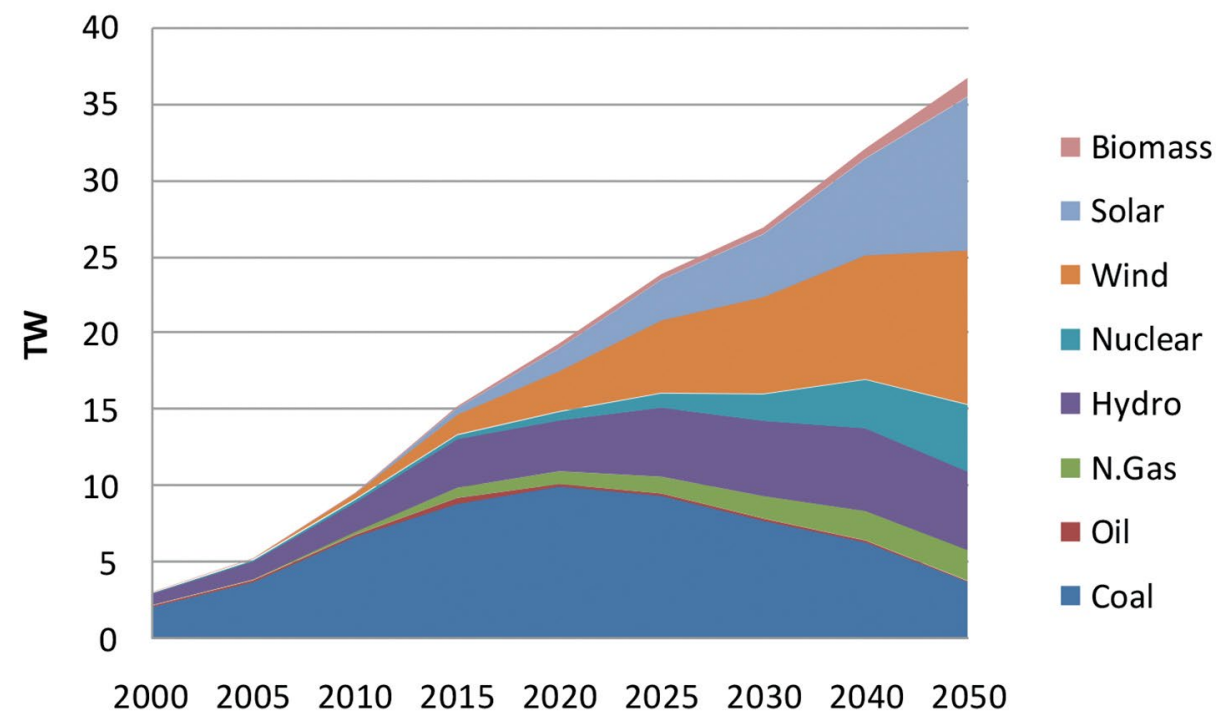

Figure 14.6 Installed capacity in China under the $2^{\circ} \mathrm{C}$ scenario Source: Jiang et al. (2013).

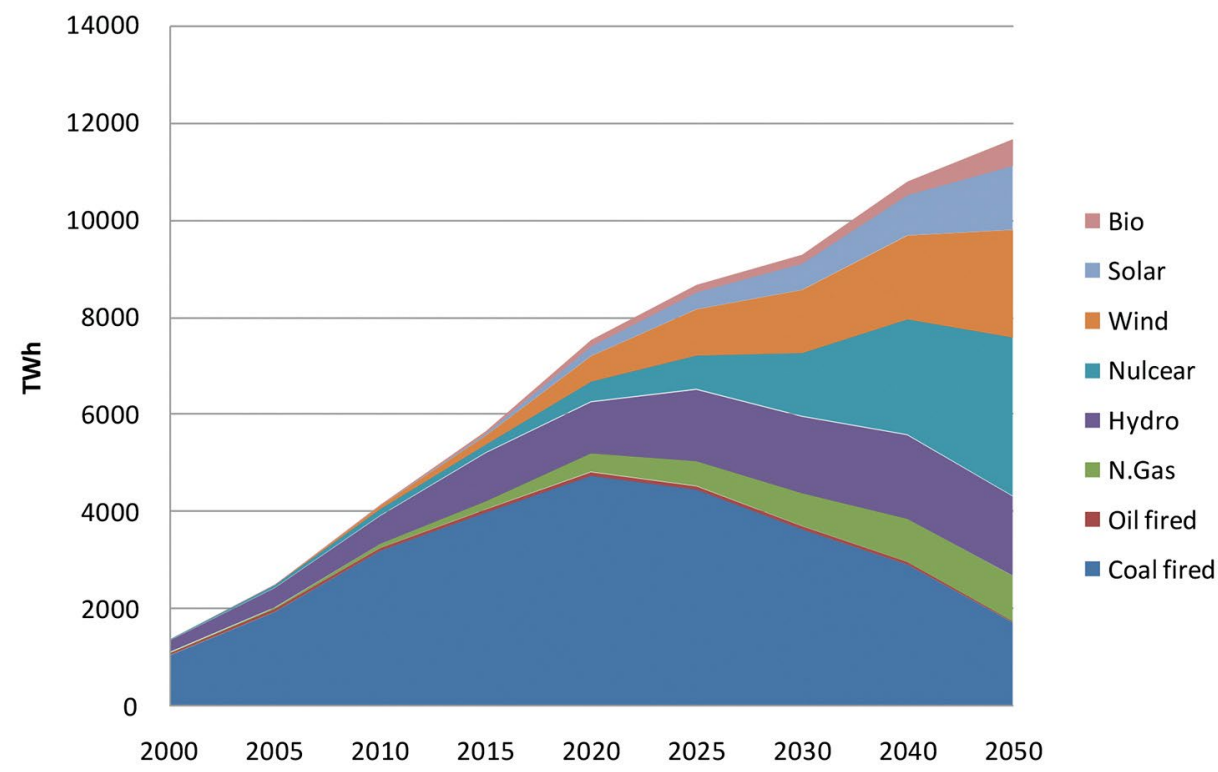

Figure 14.7 Power generation in China under the $2^{\circ} \mathrm{C}$ scenario Source: Jiang et al. (2013). 


\section{References}

China Electricity Council (CEC) (2017), Annual Information on Power Industry in China. Beijing: NEA.

Jiang, K., Zhuang X., Miao, R. and He, C. (2013), China's Role in Attaining the Global 2 Target, Climate Policy 13(S01): 55-69. dx.doi.org/10.1080/14693 062.2012.746070.

National Bureau of Statistics of China (NBS) (2016), China Statistics Yearbook 2016, Beijing: China Statistics Press.

National Bureau of Statistics of China (NBS) Energy Statistics Division (2016), China Energy Statistics Yearbook 2016, Beijing: China Statistics Press.

National Development and Reform Commission (NDRC) (2007), Medium and Long-Term Development Plan for Renewable Energy in China, Beijing: NDRC.

National Energy Administration (NEA) (2016), China's 13th Five Year Plan on Energy. Beijing: NEA.

National Energy Administration (NEA) (2017), China's 13th Five Year Plan on Renewable Energy. Beijing: NEA.

National Energy Administration (NEA) (2017), China's 13th Five Year Plan on Hydro-power. Beijing: NEA.

Renewable Energy Policy Network for the 21st Century (Ren21) (2016), Renewables 2016 Global Status Report, Paris: Ren21 Secretariat. Available from: www.ren21. net/gsr-online/.

The State Council of the People's Republic of China (State Council) (2011), Twelfth Five-Year Plan 2011-2015. Available from: english.gov.cn/. 
This text is taken from China's New Sources of Economic Growth: Human Capital, Innovation and Technological Change, Volume 2, edited by Ligang Song, Ross Garnaut, Cai Fang and Lauren Johnston, published 2017 by ANU Press, The Australian National University, Canberra, Australia.

dx.doi.org/10.22459/CNSEG.07.2017.14 